\title{
Gynecological and urological disorders among female sailors during offshore racing: concerning 10 participants in the 2013 Mini-Transat
}

\author{
Loddé $\mathrm{B}^{1,2}$, Lacroze $\mathrm{G}^{3}$, Pougnet $\mathrm{L}^{2,4}$, Fimbault JC $\mathrm{C}^{2,3}$ and Pougnet $\mathrm{R}^{2,5 *}$ \\ ${ }^{1}$ European University of Brittany (UBO), France \\ ${ }^{2}$ French Society of Maritime Medicine, France \\ ${ }^{3}$ Emergency Unit, Hospital of Douarnenez, France \\ ${ }^{4}$ Military Hospital, Clermont-Tonnerre, France \\ ${ }^{5}$ Centre Atlantique de Philosophie (CAPHI), France
}

\begin{abstract}
Background: Over the years, the number of women crew members on board racing yachts has been increasing. However, offshore racing does not distinguish between the performance of men and women.

Objectives: The main objective of this study is to evaluate the gynaecological and urological health issues encountered by female skippers in the 2013 Mini Transat.

Material and method: This is a descriptive study, based on questionnaires and medical examinations. The latter were performed before the start of the race, at Douarnenez, at the beginning of October 2013 and completed at Pointe à Pitre at the end of November 2013. Ten female skippers, aged between 26 and 53 years, were included.

Results: The absence of contraception was noted in $50 \%$ of cases, the occurrence of acute simple cystitis in three out of ten cases which was associated with a lack of hydration and poorer intimate hygiene than when on land. There were no emergency gynaecological disorders to treat during the race. Frequent episodes of buttocks folliculitis were identified.
\end{abstract}

Conclusion: These different aspects led us to consider performing a gynaecological examination before the start of an offshore race, with screening for pregnancy, and also improving the antibiotic treatments contained in the on-board medicine chest.

\section{Introduction}

The maritime world undergoes profound sociological changes in recent years, with in particular the increase in the number of women [1]. This is seen in maritime transports, naval forces, offshore racing. Some articles have shown that women adopt the same behaviours as men and had comparable risk behaviours in the face of the same occupational risks $[2,3]$. Yet there are differences between men and women at sea, if only by their physiology. This is particularly the case for professional divers: women often have shorter and different careers [4]. In recreational boating, differences in psychology explain differences in behaviour [5].

This feminization is particularly visible in offshore races. The increase in the number of women taking part in offshore yacht racing, particularly with $100 \%$ female crews, as in the 2014 Volvo Ocean Race, along with their achievements (Florence Arthaud, winner of the 1990 Route du Rhum and Ellen McArthur, winner of the Vendée Globe in 2000) bring up new issues for consideration related to the physiology, preparation and medical monitoring of these yachtswomen. When looking at sailing conditions, it is noticeable that the majority of sporting events do not distinguish between men and women in terms of route, equipment, start time or competition between individuals. They are, in fact, mixed whereas in other high-performance competitive sporting activities, such as cycling, skiing or running, competition conditions are categorized according to gender.

Despite this feminization, there is little data on the health characteristics of women skippers. However, we know that some sports have effects on the gynaecological and urological health. For example, stress alters the symptoms of endometriosis [6]. Or, excessive physical activity can give a PCOS-like (polycystic ovary syndrome-like) [7]. This is why the purpose of this article was to study the health of women captains of racing ships, from a gynaecological and urological point of view, and to analyse health events during a race.

\section{Material and method}

It was a prospective study, among women captain during the 2013 Mini-Transat race. This is a single-handed race, on board of a $6 \mathrm{~m} 50$

${ }^{\star}$ Correspondence to: Pougnet Richard, French Society of Maritime Medicine (SFMM), 117 bis, rue Jules Lesven, 29200 Brest, France, E-mail: richard. pougnet@live.fr

Key words: woman, offshore racing, gynecological disease, cystitis, medicine chest

Received: October 08, 2018; Accepted: November 05, 2018; Published: November 08, 2018 
yacht (21' 4"), between the French coast and the islands of the French Caribbean every two years.

The population studied was: all female subjects who had started the 2013 race and who had agreed to take part in our survey. From a medical point of view, in order to take part in this race, all the participants had to have completed a stress test (which must be normal), a cardiac ultrasound scan (normal) and have filled in a form detailing their medical history. The final medical authorization to participate was determined by a compulsory medical consultation at Douarnenez, before the start, based on the data supplied above. The exclusion criteria were: being a man; having refused to participate in the study; not having started the race.

The study was designed to combine a questionnaire and a gynaecological examination. A questionnaire was drawn up based on the clinical experience of doctors supervising the offshore races. In the first part, the questions dealt with the general state of health, the gynaecological and urological history, the treatments, the gynaecological follow-up. In a second part, the subjects were asked about health events during the transatlantic race. The questionnaires were tested on a sample of women not participating in the study and no questions were redrafted following this test.

The questionnaires were filled in after the skippers' agreement to participate in the study had been collected. The medical examinations took place during the obligatory medical consultations before the start of the race, at the port of Douarnenez. These were conducted in French, English or Spanish if necessary. They were performed in dedicated examination rooms. A second consultation took place on arrival at Pointe à Pitre, at the end of November 2013, for those who had succeeded in crossing the Atlantic. For the others, a telephone call was made, or an email sent.

The data were collected and then analyzed using the Excel" program. Statistical comparisons were performed using a t Student test.

\section{Results}

\section{Description of the population sample}

The study population was international as the 10 skippers came from 7 different countries. There was $100 \%$ participation in the study by the target population (Table 1). Out of the 7 skippers at the start in Sada, only 5 reached Pointe à Pitre. But, only 8 women responded to the finish questionnaire, in spite of relances.

Half of the women used contraception (Table 1). The methods of conception were varied, from an estrogen-progestin pill, to a vaginal ring, to an intrauterine device. The majority of the competitors continued to use their method of contraception during the race in order to limit menstrual discomfort (three women used oestrogenprogestin pill, one intrauterine device and one vaginal ring).

The gynaecological examination before the start only involved the yachtswomen who were using contraception. This involved a breast examination, pelvic examination and Pap smear. There was no pregnancy screening before the race, nor ultrasound scan.

The majority of women added sanitary protection to their onboard medicine chest as well as antibiotics to use as first-line treatment for cystitis. In fact, the on-board medicine chest only contained Amoxicillin and Clavulanic Acid medication and also a quinolones medication. Three women out of ten chose to add single-dose Fosfomycin-Trometamol as an antibiotic treatment on the advice of their friends and family or their doctor.

Table 1. Population of the study
\begin{tabular}{|l|l|l|}
\hline Item & Subitem & Results \\
\hline \multirow{3}{*}{ Anthropological data } & Mean age & $\begin{array}{l}36.6(26-53) \\
1 \text { menopausal woman }\end{array}$ \\
\cline { 2 - 3 } & BMI & $\begin{array}{l}23.1(18-28.8) \\
1 \text { woman in overweight }\end{array}$ \\
\hline \multirow{3}{*}{ Gynaecological history } & nulliparity & $9(90 \%)$ \\
\cline { 2 - 3 } & Abortion & $1(10 \%)$ \\
\cline { 2 - 3 } & $>1$ vulvitis in life & $5(50 \%)$ \\
\hline Urological history & $>1$ cystitis in life & $5(50 \%)$ \\
\hline Treatment & contraception & $5(50 \%)$ \\
\hline Examinations & Gynaecological examination & $10(100 \%)$ normal \\
\hline & Breast examination & $10(100 \%)$ normal \\
\hline
\end{tabular}

\section{Physiological data and hygiene habits during navigation:}

Out of the 5 who completed the race, the average weight loss was $2.4 \mathrm{~kg}[1 \mathrm{~kg}-3 \mathrm{~kg}], \sigma=1.28$, representing an average of $4.12 \%$, [1.5$4.8 \%], \sigma=1.73$.

Out of these four women without contraception, only one occasional experienced pain due to premenstrual syndrome, the others were pain-free during this period.

The average was 5 voids per day, $[2-7$ voids], $\sigma=1.73$. This number depended on the daily fluid intake which varied from $1 \mathrm{~L}$ to $5 \mathrm{~L}$, averaging from $3 \mathrm{~L} / 24 \mathrm{~h}, \sigma=1.52$.

Half of the women performed daily cleansing, mainly with wipes (whether alcohol-based, antiseptic wipes or intimate wet wipes or baby wipes). Four women chose soap and water, particularly after the passage through the Canary Islands. The yachtswomen did not wash their hands before their intimate cleansing routine. The number of weekly changes of underwear fell between 1 and 7 times, with an average of 2.9 changes per week, $\sigma=1.95$.

\section{Health event during the race}

There were two types of health problems: buttocks folliculitis and cystitis (Table 2). Three yachtswomen out of ten had buttocks folliculitis, the average number of weekly changes of underwear in this group was $1.6[1-2] \sigma=0.58$, and the average number of times they cleaned intimate areas was $4.5 /$ week [2-7] $\sigma=3.5$.

There were three episodes of cystitis, with pollakiuria as the clinical sign, in all cases, and a burning sensation when urinating in two out of three cases. The treatment implemented did not require a medical call. The skippers used their own knowledge and the yacht's medical guide to self-medicate. The medication consisted of a dose of Ciprofloxacin for 5 days, a single dose of Fosfomycin and a symptomatic hyperhydration medication.

Two out of three urinary infections occurred in skippers who were rather poorly hydrated: between $1 \mathrm{~L}$ and $1.5 \mathrm{~L}$ per day. The third had an average fluid intake of 3.5 per day. However, there was no significant difference between the "cystitis" group and the "healthy" group. The number of daily voids did not seem to influence the occurrence of cystitis. It varied between 2 and 7 voids per day in the skippers who had a mild urinary infection, an average of 5.33 voids per day in the "cystitis" group [2-7 voids] and 4.75 voids per day in the "healthy" group [4-5 voids]. Regarding the intimate cleansing routines, two women out of three had acute cystitis and only cleansed twice a week, compared with the majority of the women who cleansed 7 times: an average of 3.6 intimate cleansing routines in the "cystitis" group [2-7], and 6 weekly cleansing routines in the "healthy" group, [3-7 cleansing 
Table 2. Health issues during offshore race

\begin{tabular}{|c|c|c|c|c|c|c|c|}
\hline Skipper & Cystitis & $\begin{array}{c}\text { Number of } \\
\text { urinations per day }\end{array}$ & Daily fluid intake & $\begin{array}{l}\text { Intimate cleansing } \\
\text { routines per week }\end{array}$ & Cleansing methods & Cystitis medication & $\begin{array}{c}\text { Number of changes } \\
\text { per week }\end{array}$ \\
\hline A & No & 5 & - & 7 & Wipes, soap + water & - & 7 \\
\hline $\mathrm{B}$ & No & 5 & $3 \mathrm{~L}$ & 7 & $\begin{array}{l}\text { Alcohol-based } \\
\text { antiseptic wipes }\end{array}$ & - & 3 \\
\hline $\mathrm{C}$ & $\begin{array}{l}\text { yes, burning when } \\
\text { urinating, pollakiuria }\end{array}$ & 2 & $1 \mathrm{~L}$ & 2 & Baby wipes & $\begin{array}{l}\text { Ciprofloxacin for } \\
5 \text { days }\end{array}$ & 2 \\
\hline $\mathrm{D}$ & No & - & - & - & Wipes, soap + water & - & \\
\hline $\mathrm{E}$ & No & - & - & - & Wipes & - & \\
\hline $\mathrm{F}$ & No & 4 & $4 \mathrm{~L}$ & 7 & Baby Wipes & - & 2 \\
\hline G & $\begin{array}{l}\text { yes, burning when } \\
\text { urinating, pollkiuria }\end{array}$ & 7 & $3.5 \mathrm{~L}$ & 7 & Wipes & Fosfomycin & 1 \\
\hline $\mathrm{H}$ & No & 5 & $5 \mathrm{~L}$ & 3 & Wipes, soap + water & - & 3 \\
\hline I & yes, pollakiuria & 7 & $1.5 \mathrm{~L}$ & 2 & $\begin{array}{l}\text { Alcohol-based } \\
\text { antiseptic wipes }\end{array}$ & 0 & 2 \\
\hline $\mathrm{J}$ & No & - & - & - & Wipes, soap + water & - & - \\
\hline
\end{tabular}

routines]. The changes of underwear showed no significant difference between the two groups.

\section{Discussion}

The study population was restricted to solo female skippers as the subject of this study focused on gynaecological and urological problems. Women captain of racing ships had cystitis and folliculitis.

Due to the weakness of the population sample, it was not possible to draw statistical conclusions which could be extrapolated to a general population. The low number of female skippers (a total of ten), leads to attrition and selection bias. It is the first study in this field and it would be interesting to expand these data in larger scale studies. However, this study was the first of its kind. It showed the first results on the health events in women, except accidentology, occurring during offshore races. It also showed the feasibility of such study. These results should be complemented by new studies including more women.

The age of the skippers broadly corresponds to the average age of female skippers in other offshore races (Volvo Ocean Race, Vendée Globe, Route du Rhum...). This is sufficiently representative to make analysis of different profiles possible, from women of child-bearing age to those of menopausal age. Their BMI at $23.1 \mathrm{~kg} / \mathrm{m}^{2}$ corresponds to an average value in the general population. This value is often raised in a high-performance athlete [8], due to a higher ratio of lean body mass to fat body mass [9]. However, the weight loss during offshore races is significant [10]. It is linked to a calorie intake which is too low in relation to daily energy expenditure. According to Bigard et al, the calorie expenditure from offshore sailing can reach 4000 to 5000 Calories per day [11]. The dietary requirements of racing should, therefore, be reviewed for these yachtswomen.

The presence of three cases of acute cystitis among the yachtswomen seems comparable, in prevalence, to the level of this disorder within the general population. In fact, when Jacqueline Jolleys studied the occurrence of urinary infections in 661 women from 1987 to 1989 , she found $35 \%$ acute simple cystitis within this population [12]. The average level of hydration is insufficient for skippers which is confirmed by our study with an average hydration level of $3 \mathrm{~L} / 24 \mathrm{~h}$, bearing in mind that the total authorized volume of water allowed during the race is $180 \mathrm{~L}$ (excluding drinks containing stimulants used by many skippers to fight fatigue) [8]. That being said, the number of voids per day on the mini 6.50 corresponds to the average number of voids on land [13]. Wipes are the main items of intimate hygiene as their use is easy and rapid [14]. Nevertheless, the number of voids, the number of intimate cleansing routines, the average quantity of water drunk (in this type of competition) by the yachtswomen in our study had little, if any, bearing on the occurrence of urinary infection among them. Given the fact that our sample size is small, we cannot, therefore, draw statistical conclusions in this matter, particularly in the light of other work which reported on other, well documented, risk factors such as hypo-hydration $[8,15,16]$.

The majority of women who had cystitis two to three had already had a urinary infection during previous offshore races. Therefore, we can assume that there is a high likelihood of recurrence when they have already had this type of problem during other transats [17]. Prevention targeted at the risk factors from previous outbreaks should be discussed with the yachtswomen in order to improve their comfort during the race and consequently their performance. For the treatment of these women, the recommended first-line antibiotic should be fosfomycin and trometamol in a single dose [13,18]. Indeed, fluoroquinolones only take $3^{\text {rd }}$ place in prescriptions. It is worth remembering that fluoroquinolones are photosensitive and efficient solar protection is needed which is difficult to control at sea. The second troublesome side effect of sporting activities is tendonopathies. It seems that treatment for this category of illness is excluded from the on-board medicine chest.

Regarding gynaecological history, it should be noted that none of the women had carried a pregnancy to term. Perhaps for these women, the time dedicated sailing took precedence over creating a family. Added to this were the two abortions within the group of yachtswomen.

The episodes of candida vulvovaginitis among the yachtswomen did not appear to be trivial [14]. The occurrence depends on the activation of a saprophytic colonization linked to different factors, notably environmental, which are: synthetic underwear and tightlyfitting clothing which give rise to a moist environment which, in turn, favours the proliferation of micro-organisms [19]. The skippers in the study had diverse and varied forms of contraception, the most popular being the estrogen-progestin pill. It was found in the Frankovitch and Lebrun study that estrogen-progestin, in the absence of weight gain compared with normal weight, did not change the $\mathrm{VO} 2$ max and did not limit performance [20]. There is no particular form of contraception specifically for sportswomen, but a form of contraception suited to the needs and the hormonal profile of the individual sportswoman would limit side effects or unplanned discontinuation of contraception.

As for dermatological infections, the prevalence of folliculitis should raise the question of the germs involved. It is likely that maceration, due to sitting positions and humidity on board, and lack of 
hygiene favour these infections. The women in this study did not wash or change each day for lack of time. However, some may be colonized by germs such as Staphylococcus aureus secreting the Panton Valentine Leukocidine. This is described in professional mariners [21,22]. Microbiological analyses could be done to screen such germs. Specific hygiene treatments could then be prescribed to reduce the occurrence of this pathology.

\section{Conclusion}

This study, in spite of its many biases, focuses on the day-to-day approach of yachtswomen to their personal hygiene during a solo Atlantic crossing. The pathologies encountered by these women were acute cystitis and foliculitis. The lack of personal hygiene, hand hygiene, and insufficient hydration could favour the appearance of these pathologies. Other studies should complete these first findings. This would guide the recommendations for the medical follow-up of the yachtswomen. A reflection on the shipboard pharmacy should be conducted. The modifications to the on-board medicine chest should focus on antibiotic treatment and favour single-dose treatment for cystitis. Quinolones should not be used because of their side effects. Better use of these medications would allow an improvement in sporting performance and progress towards equity among skippers.

\section{References}

1. Stannard S, Vaughan C, Swift O, Robinson G, Altaf SA, et al. (2015) Women seafarers' health and welfare survey. Int Marit Health 66: 123-138. [Crossref]

2. Moen BE, Koefoed VF, Bondevik K, Haukenes I (2008) A survey of occupational health in the Royal Norvegian Navy. Int Marit Health 59: 35-44. [Crossref]

3. Hansen HL1, Jensen J (1998) Female seafarers adopt the high risk lifestyle of male seafarers. Occup Environ Med 55: 49-51. [Crossref]

4. Nathan D, Apu NA (1998) Women's independent access to productive resources: fish ponds in the Oxbow Lakes Project, Bangladesh. Gend Technol Dev 2: 397-413. [Crossref]

5. Irgens $\AA$, Troland K, Grønning M (2017) Female professional divers. Similarities and differences between male and female professional divers. Int Marit Health 68: 60-67. [Crossref]

6. Wester M, Eklund B (2011) My husband usually makes those decisions: gender, behavior, and attitudes toward the marine environment. Environ Manage 48: 70-80. [Crossref]
7. Cuevas M, Flores I, Thompson KJ, Ramos-Ortolaza DL, Torres-Reveron A, et al. [2012] Stress exacerbates endometriosis manifestations and inflammatory parameters in an animal model. Reprod Sci 19: 851-862. [Crossref]

8. Coste O, Paris F, Galtier F, Letois F, Maïmoun L, et al. (2011) Polycystic ovary-like syndrome in adolescent competitive swimmers. Fertil Steril 96: 1037-1042. [Crossref]

9. Mooses M, Hackney AC (2017) Anthropometrics and Body Composition in East African Runners: Potential Impact on Performance. Int J Sports Physiol Perform 12: 422-430. [Crossref]

10. Banfi G, Colombini A, Lombardi G, Lubkowska A (2012) Metabolic markers in sports medicine. Adv Clin Chem 56: 1-54. [Crossref]

11. Jolleys JV (1990) The reported prevalence of urinary symptoms in women in one rural general practice. Br J Gen Pract 40: 335-337. [Crossref]

12. Bigard AX, Guillemot PY, Chauve JY, Duforez F, Portero P, et al. (1998) Nutrient intake of elite sailors during a solitary long-distance offshore race. Int J Sport Nutr 8: 364-376. [Crossref]

13. Martin Lopez JE (2015) Candidiasis (vulvovaginal). BMJ Clin Evid 2015. [Crossref]

14. Temple JG (1972) Perineal hygiene in the prevention of recurring cystitis in women. Proc R Soc Med 65: 169. [Crossref]

15. Lowe NK, Ryan-Wenger NA (2003) Military women's risk factors for and symptoms of genitourinary infections during deployment. Mil Med 168: 569-574. [Crossref]

16. Beetz R (2003) Mild dehydration: a risk factor of urinary tract infection? Eur J Clin Nutr 57 Supp1 2: S52-58. [Crossref]

17. Warren JW (2001) Practice guidelines for the treatment of uncomplicated cystitis. Curr Urol Rep 2: 326-329. [Crossref]

18. Winberg J (1994) What hygiene measures are advisable to prevent recurrent urinary tract infection and what evidence is there to support this advice? Pediatr Nephrol 8: 652. [Crossref]

19. Grigoryan L, Trautner BW, Gupta K (2014) Diagnosis and management of urinary tract infections in the outpatient setting: a review. JAMA 312: 1677-1684. [Crossref]

20. Frankovich RJ, Lebrun CM (2000) Menstrual cycle, contraception, and performance. Clin Sports Med 19: 251-271. [Crossref]

21. Toret Labeeuw F, Huchon C, Popowski T, Chantry A, Dumont A, et al. (2013) Routine ultrasound examination by $\mathrm{OB} / \mathrm{GYN}$ résidents increase the accuracy of diagnosis for emergency surgery in gynaecology. World J of Emerg Surg 8: 16 .

22. Loddé B, Pougnet R, Roguedas-Contios AM, Eusen Y, Pougnet L, et al. (2013) Skin infection by Staphylococcus aureus in a fisherman: difficulty in continuing work on board. Int Marit Health 64: 126-128. [Crossref]

Copyright: (C2018 Loddé B. This is an open-access article distributed under the terms of the Creative Commons Attribution License, which permits unrestricted use, distribution, and reproduction in any medium, provided the original author and source are credited. 